\title{
PRODUTIVIDADE E QUALIDADE FISIOLÓGICA DE SEMENTES DE CULTIVARES DE TRIGO EM DIFERENTES DENSIDADES DE SEMEADURA
}

Jéssica de Lucena Marinho, José Henrique Bizzarri Bazzo, Carolina Pereira Cardoso, Claudemir Zucareli, Inês Cristina de Batista Fonseca

Universidade Estadual de Londrina - UEL, Programa de Pós Graduação em Agronomia, Londrina, PR. E-mail: jlmarinho@live.com

\section{RESUMO}

A determinação da densidade ótima de semeadura do trigo, adequada ao genótipo e ao ambiente, é essencial para evitar o acamamento e a competição entre as plantas, o que pode reduzir a produtividade e a qualidade das sementes. Neste sentido, objetivou-se avaliar o efeito da densidade de semeadura (nas cultivares BRS Sabiá e BRS Gralha-Azul) na produtividade e na qualidade fisiológica de sementes de duas cultivares de trigo. As sementes foram produzidas no campo experimental da Empresa Brasileira de Pesquisa Agropecuária, em Londrina-PR, no Centro Nacional de Pesquisa de Soja (Embrapa Soja) em delineamento experimental de blocos casualizados em esquema fatorial $2 \times 4$, com quatro repetições. Foram realizadas as seguintes avaliações: produtividade de sementes, massa de mil sementes, germinação, primeira contagem da germinação, comprimento e massa seca de plântulas, envelhecimento acelerado, emergência de plântulas em areia e índice de velocidade de emergência. De modo geral, observou-se que o aumento da densidade de semeadura melhora a produtividade das sementes e não altera a geminação e a emergência de plântulas de ambas cultivares. A cultivar BRS Gralha-Azul mostrou-se mais produtiva que a BRS Sabiá. $O$ aumento da densidade de semeadura aumenta o vigor das sementes para a cultivar BRS Sabiá e reduz para a cultivar BRS Gralha-Azul.

Palavras-chave: genótipo; população de plantas; potencial fisiológico; Triticum aestivum; vigor.

\section{PRODUCTIVITY AND PHYSIOLOGICAL QUALITY OF SEEDS OF WHEAT CULTIVARS IN DIFFERENT SEEDING DENSITY}

\begin{abstract}
Determination of optimum wheat sowing density, adequate to the genotype and the environment, is essential to avoid lodging and competition between plants, which can reduce seed productivity and quality. In this sense, the objective of this study was to evaluate the effect of seeding density (in cultivars BRS Sabiá e BRS Gralha-Azul) on productivity and physiological quality of seeds of two wheat cultivars. The seeds were produced in the experimental field of the Brazilian Agricultural Research Corporation, in Londrina-PR, at the National Center for Soy Research (Embrapa Soja) in experimental design of randomized blocks in a $2 \times 4$ factorial scheme, with four replications. The following evaluations were performed: seed productivity, thousand seeds mass, first count of germination, germination, seedling length, seedling dry weight, accelerated aging, seedling emergence in sand and emergency speed index. In general, the increase in seed density increases seed production and does not alter germination and emergence of seedlings of both cultivars. The cultivar BRS Gralha-Azul proved to be more productive than BRS Sabiá. The increase in seeding density increases seed vigor for BRS Sabiá cultivar and reduces to BRS Gralha-Azul cultivar.
\end{abstract}

Keywords: genotype; population of plants; physiological potential; Triticum aestivum; seed vigor.

\section{INTRODUÇÃO}

O trigo (Triticum aestivum L.) é um cereal

que apresenta múltiplos propósitos, sendo a maior parte da produção mundial destinada a alimentação humana (MAIA et al., 2007).

No Brasil, o cultivo desse cereal se concentra nos estados do Sul do país, 
principalmente Paraná e Rio Grande do Sul, com expansão para o Centro-Oeste e o Sudeste (CONAB, 2016), contudo a instabilidade climática e a baixa rentabilidade da cultura têm reduzido a área cultivada, prejudicando $\mathrm{o}$ abastecimento interno de grãos no país (CONAB, 2017), que tradicionalmente já não supre a demanda.

O grande desafio da triticultura brasileira é alcançar a autossuficiência no abastecimento desse cereal (COMPONOGARA et al., 2015) e, para isso, torna-se fundamental o aumento da produtividade da cultura, fator que depende não somente das boas condições climáticas do ambiente e das adequadas técnicas de cultivo, mas também da qualidade das sementes utilizadas na instalação das lavouras.

Silva et al. (2011) reforçam a importância da escolha e da utilização de cultivares adaptadas as diferentes regiões de cultivo, visando o bom crescimento, desenvolvimento e desempenho agronômico das plantas para que as lavouras produzam maior quantidade de sementes, e de melhor qualidade. Segundo Marcos Filho (2015), o comportamento fisiológico das sementes está relacionado ao genótipo, entretanto, Costa et al. (2005) relataram que o ambiente de cultivo pode influenciar esta característica, conforme proporciona melhores ou piores condições climáticas às plantas durante a maturação das sementes.

Outro fator que altera diretamente a produtividade e a qualidade de sementes de trigo é a densidade de semeadura, que se destaca como um dos principais elementos na construção do rendimento das lavouras, sendo seu ajuste dependente do ambiente, da cultivar, do manejo empregado na cultura e da interação entre esses fatores (FOLONI; BASSOI, 2015).

Os genótipos são afetados de forma distinta pela densidade de semeadura (OZTURK et al., 2006) pois apresentam diferenças na capacidade de perfilhamento (TAVARES et al., 2014). Cultivares com maior potencial de perfilhamento são capazes de manter elevada a produtividade de sementes, mesmo quando cultivadas em baixas densidades, diferentemente de cultivares com baixo perfilhamento, que dependem de uma maior densidade de semeadura, já que são menos eficientes em compensar o menor número de espigas por unidade de área (VALÉRIO et al., 2009).

Segundo Ozturk et al. (2006) a densidade de semeadura é o fator que mais afeta as condições de cultivo e, além disso, influencia diretamente a capacidade de perfilhamento das plantas, a formação dos componentes de produção e, consequentemente, o rendimento e a qualidade de sementes. Nesse contexto, a determinação de uma faixa de densidade ótima na qual a cultivar em uso não tenha sua produção e qualidade alteradas, mostra-se importante para o planejamento da semeadura. Isto porque, a adequação da densidade ao genótipo e ao ambiente evita o acamamento e a competição entre as plantas, o que poderia reduzir a produtividade e a qualidade das sementes, seja pelo contato com o solo ou pela criação de um microclima favorável ao desenvolvimento de patógenos.

Neste sentido, objetivou-se avaliar o efeito da densidade de semeadura na produtividade e na qualidade fisiológica de sementes de duas cultivares de trigo.

\section{MATERIAL E MÉTODOS}

As sementes foram produzidas no campo experimental da Empresa Brasileira de Pesquisa Agropecuária, em Londrina-PR, no Centro Nacional de Pesquisa de Soja (Embrapa Soja), localizado a 23 12' 08" S, 51 10' 36" O, com altitude de $570 \mathrm{~m}$, em Latossolo Vermelho distroférrico. O clima da região é do tipo Cfa, descrito como subtropical úmido com verões quentes, segundo a classificação de Köppen.

As características químicas do solo na profundidade de $0-20 \mathrm{~cm}$, determinadas antes da instalação do experimento foram representadas por: $\mathrm{pH}\left(\mathrm{H}_{2} \mathrm{O}\right)$ : 5,3; $\mathrm{P}$ (Mehlich-1): 31,7 $\mathrm{mg} \mathrm{dm}^{-3}$; $\mathrm{H}+\mathrm{Al}: 3,46 \mathrm{cmol}_{\mathrm{c}} \mathrm{dm}^{-3} ; \mathrm{K}: 0,95 \mathrm{cmol}_{\mathrm{c}} \mathrm{dm}^{-3} ; \mathrm{Ca}: 4,8$ $\mathrm{cmol}_{\mathrm{c}} \mathrm{dm}^{-3}$; Mg: $1,87 \mathrm{cmol}_{\mathrm{c}} \mathrm{dm}^{-3}$ CTC: $10,36 \mathrm{cmol}_{\mathrm{c}}$ $\mathrm{dm}^{-3}$; saturação por bases $(\mathrm{V}): 66 \%$.

Os dados de temperatura média diária e precipitação pluviométrica durante o período de cultivo, para a área experimental, são apresentados na Figura 1. 
Figura 1. Valores de temperatura média $\left({ }^{\circ} \mathrm{C}\right)$ e precipitação pluviométrica $(\mathrm{mm})$ diários durante o período de produção de sementes em campo. Londrina, PR.

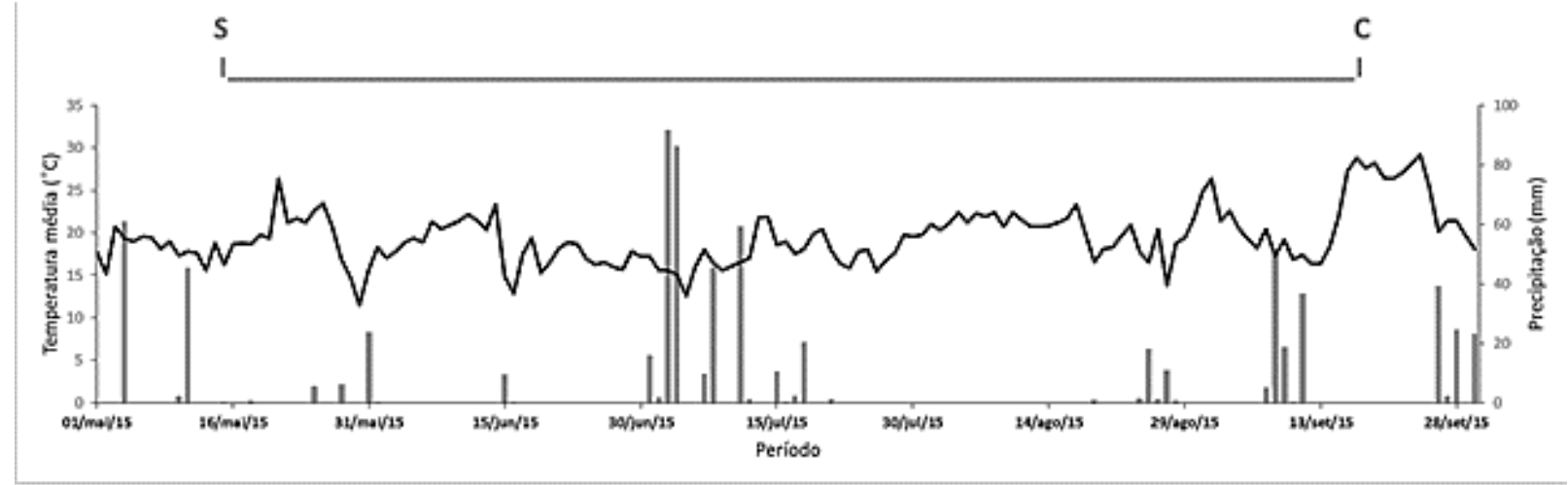

S: semeadura; C: colheita.

Foram avaliadas duas cultivares de trigo com diferentes características agronômicas e qualidades industriais, sendo elas: BRS Sabiá (ciclo precoce, trigo tipo pão, menor capacidade de perfilhamento e ampla adaptação) e BRS Gralha-Azul (ciclo médio, trigo tipo pão/melhorador, perfilha bem em todas condições de cultivo e possui ampla adaptação).

$O$ delineamento experimental utilizado foi o de blocos casualizados em esquema fatorial $2 \mathrm{x}$ 4, com quatro repetições. Os tratamentos constaram de duas cultivares (BRS Sabiá e BRS Gralha-Azul) e quatro densidades de semeadura $\left(150,250,350\right.$ e 450 sementes viáveis $\left.\mathrm{m}^{-2}\right)$.

O trigo foi cultivado sob sistema de semeadura direta, em área anteriormente ocupada com a cultura da soja. Com base nas características químicas do solo das áreas experimentais, calculou-se a adubação mineral básica no sulco de semeadura, constante para todos os tratamentos, que foi de $0 \mathrm{~kg} \mathrm{ha}^{-1}$ de $\mathrm{N}$, $50 \mathrm{~kg} \mathrm{ha}^{-1}$ de $\mathrm{P}_{2} \mathrm{O}_{5}$ e $50 \mathrm{~kg} \mathrm{ha}^{-1}$ de $\mathrm{K}_{2} \mathrm{O}$ utilizandose a fórmula 00-20-20. A semeadura foi realizada mecanicamente no dia 18 de maio. As parcelas foram compostas por 10 linhas de seis metros de comprimento e espaçamento entre linhas de 0,20 $\mathrm{m}$, com área útil de $12 \mathrm{~m}^{2}$.

Os tratamentos fitossanitários para o controle de doenças e os demais tratos culturais foram realizados conforme a necessidade e recomendações para a cultura. A colheita foi realizada após as sementes atingirem a maturação de colheita, estádio caracterizado pelo endurecimento da cariopse, plantas com aspecto seco e grãos com umidade abaixo de $20 \%$. Para determinação da produtividade e da qualidade fisiológica das sementes foram realizadas as seguintes avaliações:
Produtividade de sementes: determinada pela colheita das sementes das plantas contidas na área útil. Após a trilhagem mecânica, as sementes foram pesadas e os dados expressos em kg ha ${ }^{-1}$ corrigidos para $13 \%$ de umidade.

Massa de mil sementes: obtida mediante a contagem e pesagem de oito repetições de 100 sementes por tratamento. A média desses valores foi multiplicada por 10 para obtenção do valor da massa de 1.000 sementes, com resultados expressos em gramas (BRASIL, 2009).

Germinação: realizada com oito repetições de 50 sementes por tratamento, em papel toalha tipo Germitest ${ }^{\circledR}$, umedecido com água destilada, na proporção de 2,5 vezes a massa do substrato seco. Os rolos de papel foram mantidos sob temperatura constante de $20{ }^{\circ} \mathrm{C}$. Aos quatro (primeira contagem) e oito dias (contagem final) após a instalação do teste realizou-se a análise das sementes registrando o número de plântulas normais, sendo os resultados expressos em porcentagem (BRASIL, 2009).

Comprimento de plântulas: realizado a partir da semeadura de quatro repetições de 20 sementes por tratamento, no terço superior do papel Germitest ${ }^{\circ}$, umedecido com água destilada na proporção de 2,5 vezes a massa do substrato seco. Os rolos de papel foram acondicionados em germinador por cinco dias a $20{ }^{\circ} \mathrm{C}$ no escuro. Ao final deste período, foi efetuada a medida das plântulas normais emergidas com auxílio de uma régua graduada. Os resultados foram expressos em centímetros por plântula.

Massa seca de plântulas: as plântulas normais, obtidas a partir do teste de comprimento de plântulas foram levadas à estufa com circulação de ar forçada à $60{ }^{\circ} \mathrm{C}$ por um período de cinco dias. Após este período, cada 
repetição teve a massa avaliada em balança com precisão de 0,001g, e os resultados médios expressos em miligramas por plântula.

Envelhecimento acelerado: realizado com oito repetições de 240 sementes por tratamento em caixas plásticas tipo gerbox contendo $40 \mathrm{~mL}$ de água em seu interior, e uma tela de alumínio, sobre a qual as sementes foram distribuídas uniformemente. As caixas foram mantidas em câmara de envelhecimento acelerado, a $42{ }^{\circ} \mathrm{C}$, durante 48 horas (LIMA et al., 2006). Decorrido esse período, foi instalado o teste de germinação sob temperatura de $20{ }^{\circ} \mathrm{C}$. A contagem do número de plântulas normais foi realizada após cinco dias da instalação, com resultados expressos em porcentagem (BRASIL, 2009).

Emergência de plântulas em areia: realizado em casa de vegetação com quatro repetições de 50 sementes por tratamento, semeadas a $3 \mathrm{~cm}$ de profundidade. A areia utilizada foi previamente lavada e, em seguida, alocada em bandejas plásticas. A umidade foi mantida com irrigações de acordo com a necessidade. A avaliação do número de plântulas normais emergidas foi realizada no décimo quinto dia, com resultados expressos em porcentagem.
Índice de velocidade de emergência: conduzido em conjunto com 0 teste de emergência de plântulas em areia, por meio de contagens diárias do número de plântulas normais emergidas até a estabilização da emergência, segundo a fórmula proposta por Maguire (1962).

Os dados foram submetidos as análises de normalidade e homogeneidade dos erros e, posteriormente, à análise de variância. As médias das cultivares foram comparadas pelo teste de Tukey e os efeitos das densidades foram estudados pelo desdobramento em polinômios ortogonais até $2^{\circ}$ grau, a $5 \%$ de probabilidade.

\section{RESULTADOS E DISCUSSÃO}

Houve efeito de interação entre os fatores cultivar e densidade de semeadura para as características comprimento e massa seca de plântulas e índice de velocidade de emergência. Verificou-se efeito isolado de cultivar para as variáveis primeira contagem de germinação, germinação, massa de mil sementes e produtividade de sementes, e de densidade apenas para a produtividade de sementes (Tabela 1).

Tabela 1. Valores de quadrado médio da análise de variância das características fisiológicas das sementes e produtividade de trigo, em função de cultivares e de diferentes densidades de semeadura. Londrina-PR, 2015

\begin{tabular}{cccccccccc}
\hline & \multicolumn{10}{c}{ CARACTERÍSTICAS } \\
\cline { 2 - 10 } Fonte de variação & $\begin{array}{c}\mathrm{PC} \\
(\%)\end{array}$ & $\begin{array}{c}\mathrm{G} \\
(\%)\end{array}$ & $\begin{array}{c}\mathrm{CP} \\
(\mathrm{cm})\end{array}$ & $\begin{array}{c}\text { MSP } \\
(\mathrm{mg})\end{array}$ & $\begin{array}{c}\text { EA } \\
(\%)\end{array}$ & $\begin{array}{c}\text { EP } \\
(\%)\end{array}$ & $\begin{array}{c}\text { IVE } \\
(\%)\end{array}$ & $\begin{array}{c}\text { MMS } \\
(\mathrm{g})\end{array}$ & $\begin{array}{c}\text { PROD } \\
\left(\mathrm{kg} \mathrm{ha}^{-1}\right)\end{array}$ \\
\hline Bloco & 3.61 & 3.11 & 1.40 & 0.63 & 11.87 & 13.00 & 0.04 & 0.97 & 75083.38 \\
Cultivar (C) & $42.78^{*}$ & $16.56^{*}$ & $31.18^{*}$ & $4.12^{*}$ & 15.12 & 2.00 & 0.61 & $19.28^{*}$ & $1917890.50^{*}$ \\
Densidade (D) & 17.03 & 1.28 & $5.42^{*}$ & 1.36 & 54.20 & 28.33 & 0.51 & 0.44 & $711391.43^{*}$ \\
C*D & 24.36 & 5.61 & $12.72^{*}$ & $2.32^{*}$ & 24.37 & 9.00 & $2.67^{*}$ & 1.71 & 175675.62 \\
\hline CV (\%) & 2.44 & 1.94 & 8.33 & 11.20 & 4.95 & 4.06 & 5.96 & 3.32 & 8.52 \\
\hline
\end{tabular}

*: significativo a 5\% de probabilidade pelo teste F; CV: coeficiente de variação. PC: primeira contagem da germinação; G: germinação; CP: comprimento de plântulas; MSP: massa seca de plântulas; EA: envelhecimento acelerado; EP: emergência de plântulas em areia; IVE: índice de velocidade de emergência; MMS: massa de mil sementes e; PROD: produtividade de sementes.

Para germinação e primeira contagem verificou-se que a cultivar BRS Sabiá apresentou maiores valores para estas características em relação a BRS Gralha-Azul (Tabela 2). Entretanto, é importante ressaltar que ambas cultivares apresentaram porcentagem de germinação superior à $80 \%$, padrão mínimo estabelecido pela Instrução Normativa №. 45 (BRASIL, 2013).

Já para massa de mil sementes e produtividade observou-se que os maiores valores foram obtidos pela cultivar BRS GralhaAzul (Tabela 2). A cultivar BRS Sabiá, nas condições em que o experimento foi conduzido, produziu menos sementes, mas com velocidade de germinação e germinação total ligeiramente superiores. Isto ocorreu porque houve menor quantidade de drenos, já que a BRS Sabiá possui menor capacidade de perfilhamento (FOLONI; BASSOI, 2015) sendo assim, melhor a partição dos fotoassimilados translocados e melhor a 
qualidade das sementes produzidas (TAIZ; ZEIGER, 2009).

Segundo Sangoi et al. (2007), devido às variações genéticas entre as cultivares, diferenças no comportamento em campo são observadas, tais como capacidade de perfilhamento, ciclo de maturação, arquitetura de planta e potencial produtivo. Essas diferenças podem interferir na capacidade de absorção, assimilação e conversão de nutrientes e, consequentemente, na produtividade e qualidade final das sementes produzidas.

Tabela 2. Valores médios da primeira contagem de germinação (PC), germinação (G), massa de mil sementes (MMS) e produtividade de sementes (PROD) das cultivares de trigo BRS Gralha-Azul e BRS Sabiá. Londrina-PR, 2015

\begin{tabular}{ccccc}
\hline \multirow{2}{*}{ Genótipos } & \multicolumn{5}{c}{ CARACTERÍSTICAS } \\
\cline { 2 - 5 } & $\mathrm{PC}(\%)$ & $\mathrm{G}(\%)$ & $\mathrm{MMS}(\mathrm{g})$ & PROD $\left(\mathrm{kg} \mathrm{ha}^{-1}\right)$ \\
\hline BRS Gralha-azul & $95.00 \mathrm{~b}$ & $96.00 \mathrm{~b}$ & $27.60 \mathrm{a}$ & $3805.58 \mathrm{a}$ \\
BRS Sabiá & $97.00 \mathrm{a}$ & $98.00 \mathrm{a}$ & $26.05 \mathrm{~b}$ & $3315.95 \mathrm{~b}$ \\
\hline CV (\%) & 2.44 & 1.94 & 3.32 & 8.52 \\
\hline
\end{tabular}

*Médias seguidas de mesma letra na coluna, não diferem entre si pelo teste $F(P<0,05)$.

Diferentes genótipos apresentam desempenhos diferentes em um mesmo ambiente, seja pela diferente capacidade de adaptação aos estímulos do meio, ou pela diferença entre os ciclos, o que faz com que a fase de definição dos componentes de rendimento e a maturação ocorra em períodos distintos. Por isso, tais características (germinação, primeira contagem de germinação, massa de mil sementes e produtividade) podem ter sofrido influência do ambiente de cultivo. Porém, é importante ressaltar que a amplitude de variação entre elas não é elevada, visto que também são controladas geneticamente, principalmente a massa de mil sementes (GUARIENTI et al., 2005).

Alvarenga et al. (2009) estudando o comportamento de duas cultivares de trigo em diferentes densidades de semeadura sob irrigação, observaram que a massa de mil sementes variou significativamente de acordo com o genótipo, mas que a densidade de semeadura não exerceu influência significativa sobre esta característica, corroborando com os resultados obtidos.
Além da massa de sementes, o rendimento em trigo é determinado por outros componentes, como o número de espigas por planta, número de espiguetas por espiga, número de sementes por espiga e espigueta, que variam entre genótipos (GONDIM et al., 2008) nas mesmas condições de cultivo. Franceschi et al. (2009), trabalhando com 17 genótipos de trigo, observaram efeitos significativos para cultivares, ambientes e para a interação cultivar $\mathrm{x}$ ambiente, indicando que as cultivares possuem desempenho diferenciado diante das mesmas variações ambientais.

Para o comprimento de plântula, a cultivar BRS Sabiá ajustou-se a uma equação linear crescente em resposta ao aumento da densidade de semeadura. Já a cultivar BRS Gralha-Azul adequou-se a uma equação quadrática com ponto de mínima em 448,5 sementes $\mathrm{m}^{-2}$ (Figura 2). Com exceção da densidade de 150 sementes $\mathrm{m}^{-2}$, em que não houve diferença significativa entre as cultivares para esta característica, a cultivar BRS Sabiá apresentou os maiores valores para o comprimento de plântula. 
Figura 2. Comprimento de plântulas provenientes de sementes de duas cultivares de trigo cultivadas em diferentes densidades de semeadura. Londrina-PR, 2015. As letras iguais indicam que não há diferença significativa entre cultivares, em uma mesma densidade, pelo teste $\mathrm{F}$.

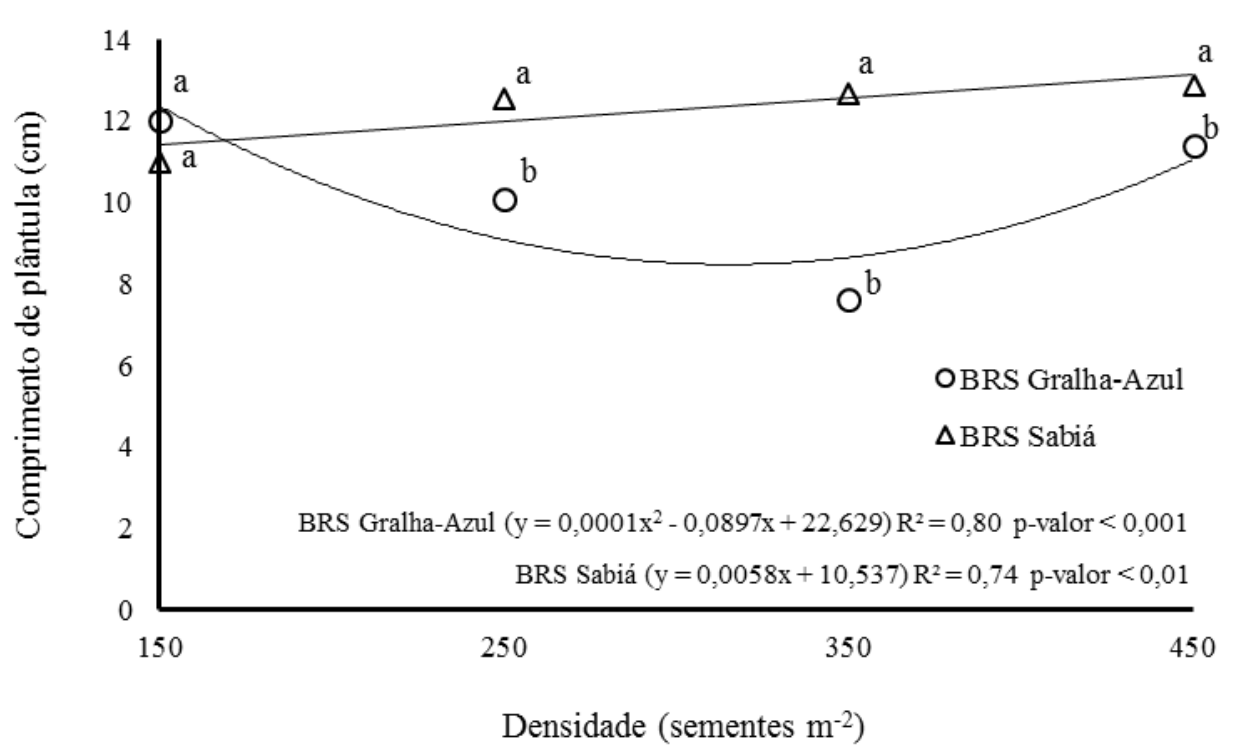

Para a massa seca de plântula as cultivares BRS Sabiá e BRS Gralha-Azul adequaram-se a funções quadrática e linear negativa, respectivamente, sendo o ponto de máxima encontrado, para a BRS Sabiá, em 319,17 sementes $\mathrm{m}^{-2}$. A cultivar BRS Sabiá obteve a maior massa seca de plântula somente na densidade de 350 sementes $\mathrm{m}^{-2}$, nas demais densidades as duas cultivares não diferiram (Figura 3).

Figura 3. Massa seca de plântula proveniente de sementes de duas cultivares de trigo cultivadas em diferentes densidades de semeadura. Londrina-PR, 2015.

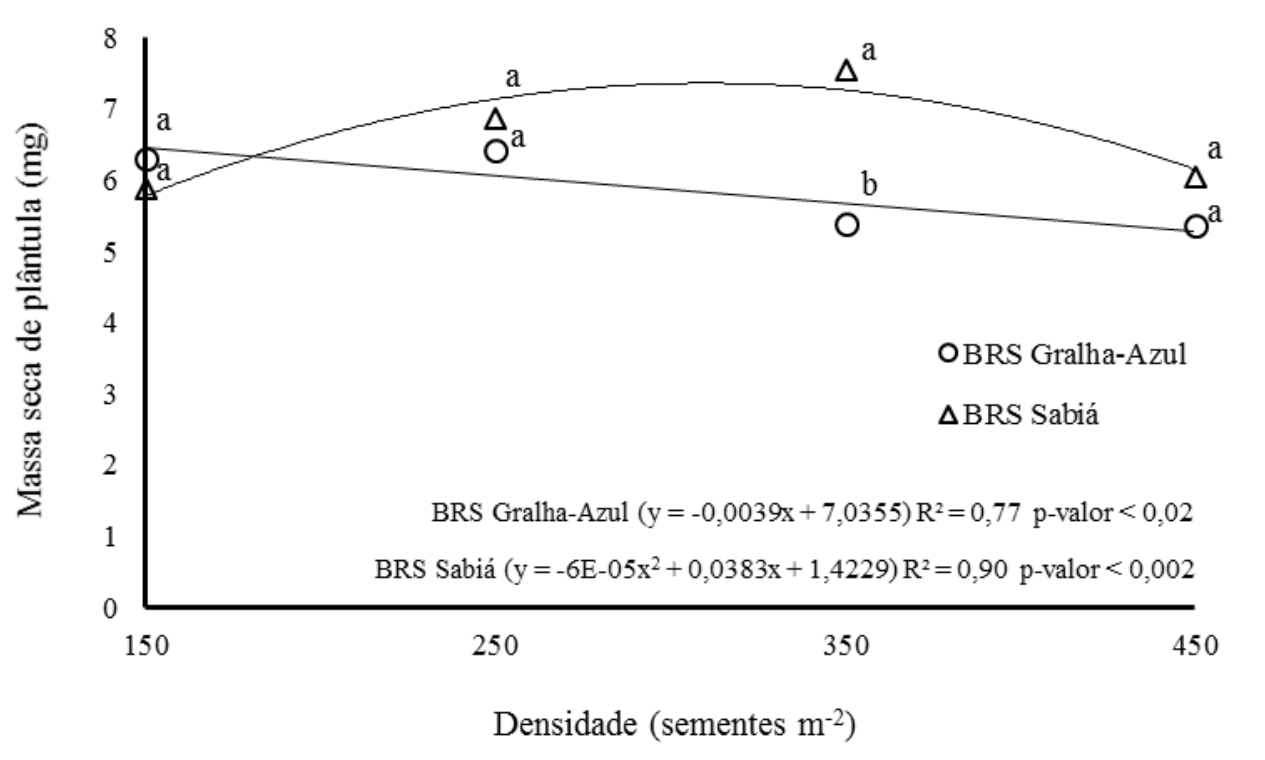

Para o índice de velocidade de emergência, ambas cultivares adequaram-se a funções quadráticas, com ponto de máxima e mínima encontrados em 287,50 e 291,66 sementes $\mathrm{m}^{-2}$ para as cultivares BRS Sabiá e BRS Gralha-Azul, respectivamente. Nas densidades de 150 e 450 sementes $\mathrm{m}^{-2}$, não foi observada diferença significativa entre as cultivares, já nas demais densidades a cultivar BRS Sabiá apresentou os melhores valores para o índice de velocidade de emergência (Figura 4). 
Figura 4. Índice de velocidade de emergência de sementes produzidas por duas cultivares de trigo em diferentes densidades de semeadura. Londrina-PR, 2015.

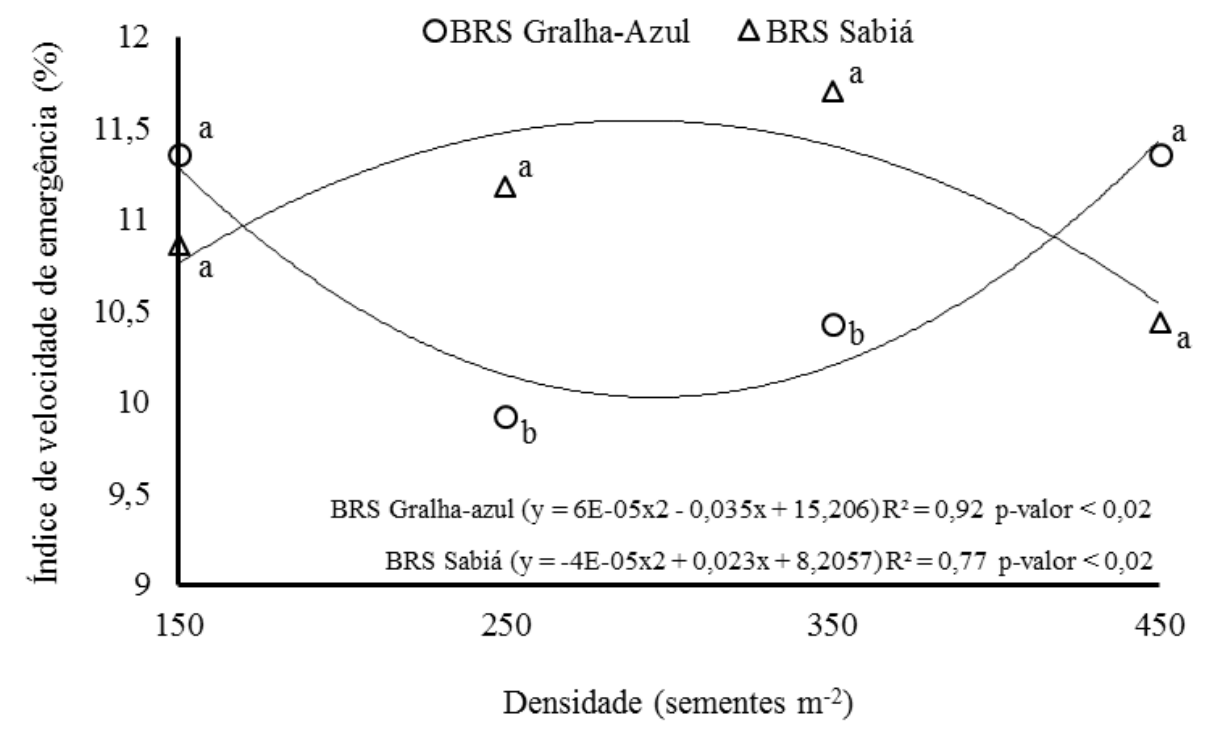

De forma geral, a cultivar BRS Sabiá apresentou os melhores resultados para comprimento e massa seca de plântula e índice de velocidade de emergência, revelando melhor capacidade em produzir sementes de maior qualidade, mesmo com variações na densidade de semeadura. Se uma cultivar não apresenta capacidade de adaptação, para superar adversidades em campo, provocadas pelo aumento populacional, a qualidade da produção final pode ser afetada negativamente, através da formação de sementes com menor potencial fisiológico, como pode ter ocorrido com a BRS Gralha-Azul.

As cultivares estudadas apresentam variação quanto à duração do ciclo de desenvolvimento, altura das plantas, potencial de perfilhamento, desempenho produtivo, suscetibilidade a doenças, acamamento, regiões de adaptação, entre outros. Por isso, foram encontrados resultados diferentes, para as duas cultivares, nas mesmas condições de cultivo. Nesse sentido, a maior produtividade da BRS Gralha-Azul pode estar relacionada ao seu ciclo de desenvolvimento, que é maior, estimado em 124 dias (BASSOI, 2012), do que o da BRS Sabiá, considerada precoce, com um ciclo de, aproximadamente, 103 dias (BASSOI; FOLONI, 2013). Entretanto, a BRS Gralha-Azul apresenta maior suscetibilidade ao acamamento, que ocorre com maior frequência em altas densidades, o que pode resultar na produção de sementes de menor qualidade.

A produtividade, também afetada pela densidade, apresentou resposta linear positiva conforme aumentou-se o número de sementes por área (Figura 5). 
Figura 5. Produtividade de sementes de trigo em função da densidade semeadura, média de duas cultivares. Londrina-PR, 2015.

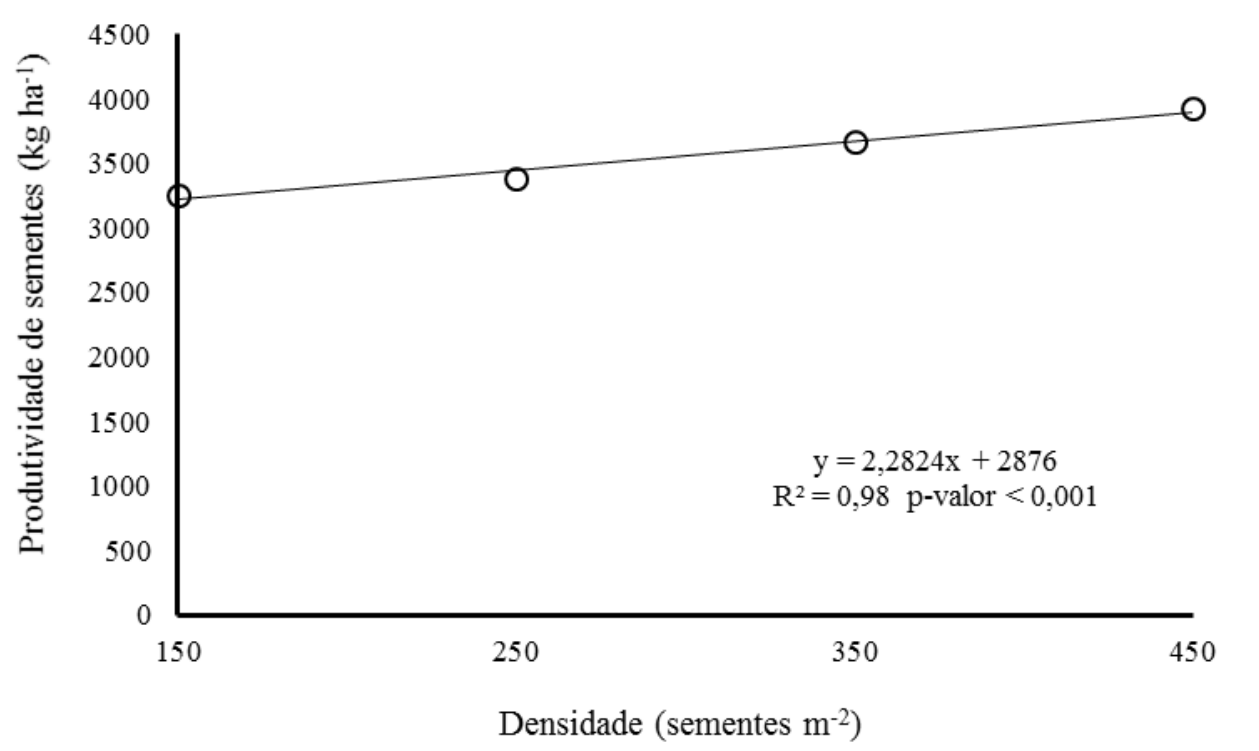

O aumento da densidade de plantas de trigo por área pode ter provocado o decréscimo de alguns dos componentes de produção, como o número de perfilhos por área. Isto ocorre devido ao menor acúmulo de matéria seca, provocado pela intensa competição intraespecífica. Contudo, a plasticidade genotípica do trigo em alterar outros componentes de produção, como o número de grãos por área, a fim de maximizar o rendimento final, pode ter contribuído para o aumento da produtividade em maiores densidades, o que explica o resultado obtido.

Por outro lado, plantas cultivadas em menores densidades têm maior acúmulo de matéria seca e, por isso, emitem maior número de perfilhos. Contudo, para se tornar produtivo, um perfilho deve exibir taxas de crescimento próximas ao do colmo principal (FIOREZE; RODRIGUES, 2014), o que não acontece com muita frequência no trigo, ou então a possibilidade de abortamento aumenta, principalmente sob estresse (ELHANI et al., 2007). Isso explica os menores resultados encontrados para produtividade em densidades mais baixas.

Valério et al. (2009), observaram em seu estudo que o maior número de perfilhos emitidos em menores populações de plantas não foram suficientes para superar o maior rendimento de sementes obtido em populações elevadas, isto porque o número de espigas por metro quadrado é maior em maiores densidades, corroborando com os resultados obtidos.

\section{CONCLUSÃO}

O aumento da densidade de semeadura aumenta a produtividade de sementes e não altera a geminação e a emergência de plântulas de ambas cultivares. A cultivar BRS Gralha-Azul mostrou-se mais produtiva que a BRS Sabiá. O aumento da densidade de semeadura, até 450 sementes $\mathrm{m}^{-2}$, aumenta o vigor das sementes para a cultivar BRS Sabiá e reduz para a cultivar BRS Gralha-Azul.

\section{REFERÊNCIAS}

ALVARENGA, C.B.; SOARES SOBRINHO, J.S.; SANTOS, E.M. Comportamento de cultivares de trigo em diferentes densidades de semeadura sob irrigação indicadas para a região do Brasil central. Bioscience Journal, Uberlândia, v.25, n.5, p. 98-107, 2009.

BASSOI, M.C. BRS Gralha-Azul cultivar de trigo: sua produtividade vai alçar altos voos. Londrina: Embrapa Soja, 2012. Disponível em: $<$ http://ainfo.cnptia.embrapa.br/digital/bitstrea $\mathrm{m} /$ item/56767/1/GRALHA-AZUL.pdf>. Acesso em: 23 jan. 2018.

BASSOI, M.C.; FOLONI, J.S.S. Trigo BRS Sabiá: mais produtividade e precocidade na sua lavoura. Londrina: Embrapa Soja, 2013. Disponível em: <http://ainfo.cnptia.embrapa.br/digital/bitstrea m/item/96166/1/Trigo-BRS-Sabia-maisprodutividade-e-prococidade-na-sualavoura.pdf>. Acesso em: 23 jan. 2018. 
BRASIL. Ministério da Agricultura, Pecuária e Abastecimento. Regras para análise de sementes. Brasília: Mapa/ACS, 2009. 399p.

BRASIL. Ministério da Agricultura, Pecuária e Abastecimento. Instrução Normativa $\mathbf{N}^{\circ} \mathbf{4 5}$ de 2013. Brasília, DF: MAPA/DAS/CSM, 2013. 38 p.

COMPONOGARA, A.; GALLIO, E.; BORBA, W.F.de.; GEORGIN, J. O atual contexto da produção de trigo no Rio Grande do Sul. Revista Eletrônica em Gestão, Educação e Tecnologia Ambiental, Santa Maria, v.19, n.2, p. 246-257, 2015.

CONAB. Acompanhamento da safra brasileira de grãos 2015/2016. 2016. Disponível em: <http://www.conab.gov.br/OlalaCMS/uploads/ar quivos/16_06_09_09_00_00_boletim_graos_junh o_2016_-_final.pdf>. Acesso em: 13 jan. 2018.

CONAB. Acompanhamento da safra brasileira de grãos 2016/2017. 2017. Disponível em: <http://www.conab.gov.br/OlalaCMS/uploads/ar quivos/17_03_14_15_28_33_boletim_graos_mar co_2017bx.pdf>. Acesso em: 13 jan. 2018.

COSTA, N.P.; MESQUITA, C.M.; MAURINA, A.C.; FRANÇA NETO, J.B.; KRZYZANOWSKI, F.C.; OLIVEIRA, M.C.N.; HENNING, A.A. Perfil dos aspectos físicos, fisiológicos e químicos de sementes de soja produzidas em seis regiões do Brasil. Revista Brasileira de Sementes, Jaboticabal, v.27, n.2, p.01-06, 2005. http://dx.doi.org/10.1590/S0101$\underline{31222005000200025}$

ELHANI, S.; MARTOS, V.; RHARRABTI, Y.; ROYO, C.; GARCÍA DEL MORAL, L.F. Contribution of main stem and tillers to durum wheat (Triticum turgidum L.var. durum) grain yield and its components grown in Mediterranean environments. Field Crops Research, v.103, n.1, p.25-35, 2007.

https://doi.org/10.1016/j.fcr.2007.05.008

FIOREZE, S.L.; RODRIGUES, J.D. Componentes produtivos do trigo afetados pela densidade de semeadura e aplicação de regulador vegetal. Semina: Ciências Agrárias, v.35, n.1, p. 39-54, $2014 . \quad$ https://doi.org/10.5433/1679$\underline{0359.2014 v 35 n 1 p 39}$

FOLONI, J.S.S.; BASSOI, M.C. Indicações fitotécnicas para cultivares BRS de trigo no
Paraná. Londrina: Embrapa Soja, 2015. (Circular Técnica; 110).

FRANCESCHI, L.; BENIN, G.; GUARIENTI, E.; MARCHIORO, V.S.; MARTIN, T.N. Fatores précolheita que afetam a qualidade tecnológica de trigo. Ciência Rural, v.39, n.5, p. 1625-1632, $2009 . \quad \quad$ http://dx.doi.org/10.1590/S0103$\underline{84782009005000060}$

GONDIM, T.C.O.; ROCHA, V.S.; SEDIYAMA, C.S.; MIRANDA, G.V. Análise de trilha para componentes do rendimento e caracteres agronômicos de trigo sob desfolha. Pesquisa Agropecuária Brasileira, v.43, n.4, p.487-493, 2008. http://dx.doi.org/10.1590/S0100204X2008000400007

GUARIENTI, E.M.; CIACCO, C.F.; CUNHA, G.R.; DEL DUCA, L.J.A.; CAMARGO, C.M.O. Efeitos da precipitação pluvial, da umidade relativa do ar e de excesso de déficit hídrico do solo no peso hectolitro, no peso de mil grãos e no rendimento de grãos de trigo. Ciência e Tecnologia de Alimentos, v.25, n.3, p. 412-418, 2005. https://doi.org/10.1590/S0101$\underline{20612005000300004}$

LIMA, T.C.; MEDINA, P.F.; FANAN, S. Avaliação do vigor de sementes de trigo pelo teste de envelhecimento acelerado. Revista Brasileira de Sementes, v.28, n.1, p. 106-113, 2006. https://doi.org/10.1590/S0101$\underline{31222006000100015}$

MAGUIRE, J.D. Speed of germination-aid in selection and evaluation for seedling emergence and vigor. Crop Science, v.2, n.2, p. 176-177, 1962.

https://doi.org/10.2135/cropsci1962.0011183X0 $\underline{00200020033 x}$

MAIA, A.R.; LOPES, J.C.; TEIXEIRA, C.O. Efeito do envelhecimento acelerado na avaliação da qualidade fisiológica de sementes de trigo. Ciência e Agrotecnologia, v.31, n.3, p. 678-684, $2007 . \quad \quad$ http://dx.doi.org/10.1590/S141370542007000300012

MARCOS FILHO, J. Fisiologia de sementes de plantas cultivadas. 2. ed. Londrina: Abrates, 2015. $660 \mathrm{p}$. 
OZTURK, A.; CAGLAR, O.; BULUT, S. Growth and yield response of facultative wheat to winter sowing, freezing sowing and spring sowing at different seeding rates. Journal of Agronomy and Crop Science, v.192, n.1, p. 10-16, 2006. http://dx.doi.org/10.1111/j.1439-

\section{X.2006.00187.x}

SANGOI, L.; BERNS, A.C.; ALMEIDA, M.L.; ZANIN, C.G.; SCHWEITZER, C. Características agronômicas de cultivares de trigo em resposta à época da adubação nitrogenada de cobertura. Ciência Rural, v.37, n.6, p.1564-1580, 2007. http://dx.doi.org/10.1590/S0103$\underline{84782007000600010}$

SILVA, R.R.; BENIN, G.; SILVA, G.O.; MARCHIORO, V.S.; ALMEIDA, J.L.; MATEI, G. Adaptabilidade e estabilidade de cultivares de trigo em diferentes épocas de semeadura, no Paraná. Pesquisa Agropecuária Brasileira, v.46, n.11, p. 1439-1447, $2011 . \quad$ http://dx.doi.org/10.1590/S0100204X2011001100004

TAIZ, L.; ZEIGER, E. Fisiologia vegetal. 4. ed. Porto Alegre: Artmed, 2009. 819 p.

TAVARES, L.C.V.; FOLONI, J.S.S.; BASSOI, M.C.; PRETE, C.E.C. Genótipos de trigo em diferentes densidades de semeadura. Pesquisa Agropecuária Tropical, v.44, n.2, p. 166-174, $2014 . \quad$ https://doi.org/10.1590/S1983$\underline{40632014000200010}$

VALÉRIO, I.P.; CARVALHO, F.I.F.; OLIVEIRA, A.C.; BENIN, G.; MAIA, L.C.; SILVA, J.A.G.; SCHIMIDT, D.M.; SILVEIRA, G. Fatores relacionados à produção e desenvolvimento de afilhos em trigo. Semina: Ciências Agrárias, v.30, n.1, p. 12071218, 2009. https://doi.org/10.5433/16790359.2009v30n4Sup1p1207

Recebido para publicação em 24/05/2018

Revisado em 21/08/2018

Aceito em 29/12/2018 